\title{
Automated Ice-Tethered Profilers for Seawater Observations under Pack Ice in All Seasons
}

\author{
R. Krishfield, J. Toole, A. Proshutinsky, and M.-L. Timmermans \\ Woods Hole Oceanographic Institution, Woods Hole, Massachusetts
}

(Manuscript received 24 July 2007, in final form 8 February 2008)

\begin{abstract}
An automated, easily deployed Ice-Tethered Profiler (ITP) instrument system, developed for deployment on perennial sea ice in the polar oceans to measure changes in upper ocean water properties in all seasons, is described, and representative data from prototype instruments are presented. The ITP instrument consists of three components: a surface subsystem that sits atop an ice floe; a weighted, plastic-jacketed wire-rope tether of arbitrary length (up to $800 \mathrm{~m}$ ) suspended from the surface element; and an instrumented underwater unit that employs a traction drive to profile up and down the wire tether. ITPs profile the water column at a programmed sampling interval; after each profile, the underwater unit transfers two files holding oceanographic and engineering data to the surface unit using an inductive modem and from the surface instrument to a shore-based data server using an Iridium transmitter. The surface instrument also accumulates battery voltage readings, buoy temperature data, and locations from a GPS receiver at a specified interval (usually every hour) and transmits those data daily. Oceanographic and engineering data are processed, displayed, and made available in near-real time (available online at http://www.whoi.edu/ itp). Six ITPs were deployed in the Arctic Ocean between 2004 and 2006 in the Beaufort gyre with various programmed sampling schedules of two to six one-way traverses per day between 10- and 750-760-m depth, providing more than 5300 profiles in all seasons (as of July 2007). The acquired CTD profile data document interesting spatial variations in the major water masses of the Canada Basin, show the double-diffusive thermohaline staircase that lies above the warm, salty Atlantic layer, measure seasonal surface mixed layer deepening, and document several mesoscale eddies. Augmenting the systems already deployed and to replace expiring systems, an international array of more than one dozen ITPs will be deployed as part of the Arctic Observing Network during the International Polar Year (IPY) period (2007-08) holding promise for more valuable real-time upper ocean observations for operational needs, to support studies of ocean processes, and to facilitate numerical model initialization and validation.
\end{abstract}

\section{Background}

Perennial sea ice greatly constrains many modern automated observational systems, such as the Jason (http://sealevel.jpl.nasa.gov/mission/jason-1.html) and Argo (http://www.argo.ucsd.edu/) projects, which are returning satellite altimeter measurements of sea level anomalies and drifting profiling float measurements of the upper ocean temperature and salinity fields, all feeding a global ocean data assimilation experiment

Corresponding author address: Richard Krishfield, Department of Physical Oceanography, MS\#23, Woods Hole Oceanographic Institution, Woods Hole, MA 02543.

E-mail: rkrishfield@whoi.edu
(GODAE; http://www.usgodae.org/). The high-latitude oceans represent an observational gap in this "global" ocean observing system. There are not sufficient observations presently available to accurately quantify change in polar environmental conditions or to validate/disprove hypotheses about high-latitude climate variability. Those observations that have been made in the far north hint that the Arctic has been undergoing large changes recently. For instance, changes in the Atlantic Water and in the overlying cold halocline layer have been observed over the previous decades (e.g., Morison et al. 2000). At the same time, an ensemble of global climate models predicts the decline and eventual disappearance of the perennial sea ice cover in the Arctic within this century (ACIA 2004). These concerns 
have led to enhanced international research in the Arctic, including organization of an International Polar Year (IPY) in 2007-09. The IPY will be well served by technological innovations developed since the last international concentrated scientific and exploratory program was conducted in the polar regions during the International Geophysical Year in 1957-58. In 1957-58, physical oceanographic information was limited mostly to bottom soundings and bottle casts. Today, satellite remote sensing technology is providing daily atmosphere and sea ice data from even the most remote regions of the Arctic and Antarctic. Moreover, icebreakers and aircraft provide unprecedented access to the polar regions; and advances in microprocessor, robotic, and communication technologies has enabled the development of a variety of automated data acquisition devices. With this new technology in hand, the potential exists for much greater temporal and spatial sampling coverage of the Arctic Ocean during the IPY and beyond.

This concept has recently been discussed in the National Academy of Sciences report "Towards an Integrated Arctic Observing Network" (IAON; available online from http://www.nap.edu/catalog/11607.html). One of the observational tools considered central to sustained observations of the polar atmosphere-iceocean system is ice-based observatories (IBOs), defined by Proshutinsky et al. (2004) as "automated, drifting, ice-based sensor systems providing comprehensive data from the Arctic environment and incorporating the multidisciplinary needs of biological, chemical and physical oceanography, as well as different aspects of atmospheric and sea-ice studies." Ice-based drifters with discrete subsurface instrumentation-such as the salinity Argos buoys (SALARGOS; Morison et al. 1982), Ice-Ocean Environmental Buoy (IOEB; Honjo et al. 1995), and the Japan Agency for Marine-Earth Science and Technology (JAMSTEC) Compact Arctic Drifter (J-CAD; Kikuchi et al. 2002) - have been successfully fielded in the Arctic in the past two decades, most recently in conjunction with the North Pole Environmental Observatory (NPEO) program (http:// psc.apl.washington.edu/northpole/). These deployments demonstrate that automated buoys are viable means of acquiring long-term in situ data from beneath the ice pack. However, the vertical resolution of the temperature and salinity observations from these systems has typically been limited to only a few depths because of the costs associated with outfitting multiple sensors on a single package. Intercalibration of these strings of multiple sensors can be difficult. Moreover, even with a limited number of sensors, total system costs have meant that only a small number of such de- vices has been fielded at any one time. Another shortcoming of the ocean measurements from these systems is that limited vertical resolution potentially misses some of the small-scale Arctic Ocean structures.

Here, a newly developed IBO subsystem for acquiring ocean water property observations, the ITP (Toole et al. 2006), is described and representative data from prototype instruments are presented. Additional technical information and operation instructions are provided by Krishfield et al. (2006). We note that a similar device, the Polar Ocean Profiling System (POPS), has also been field tested recently (Kikuchi et al. 2007). These expendable instruments repeatedly profile the upper ocean water properties below the perennial ice cover and telemeter those data to shore in near-real time for public display and distribution. Plans are being developed internationally to comprehensively observe the Arctic Ocean system through the coming IPY period by building and deploying an array of IBOs that include ocean profilers along with other instrument systems.

The ITP concept was defined by the following instrument specifications:

- capable of returning in real time better than 1-mvertical-resolution, high-accuracy daily (or twice daily) temperature and salinity profiles from the ocean surface mixed layer to at least 750-m depth for up to a 3-yr period (assuming deployment in robust ice floes);

- instrument and deployment equipment are sufficiently light and compact for transport to remote sites using light aircraft (Twin Otters) and helicopters;

- profiler can be deployed through a conventional 25cm ice-augered hole;

- modestly priced, allowing them to be deployed in large numbers and considered expendable; and

- capable of supporting additional instrumentation modules for acquiring surface and/or additional subsurface measurements.

The ITP builds on the success of ice drifters, and on the Woods Hole Oceanographic Institution (WHOI)developed moored profiler (MP) instrument (Doherty et al. 1999). Like the MP, the ITP uses a small traction drive system to propel itself up and down a wire tether, collecting oceanographic observations continuously while profiling, then telemeters those data to a landbased data server. The instrument design and operational software are detailed in sections 2 and 3; deployment procedures are outlined in section 4 , and representative engineering and scientific data from prototype instruments are presented in section 5. A final section outlines present activities and future plans. 


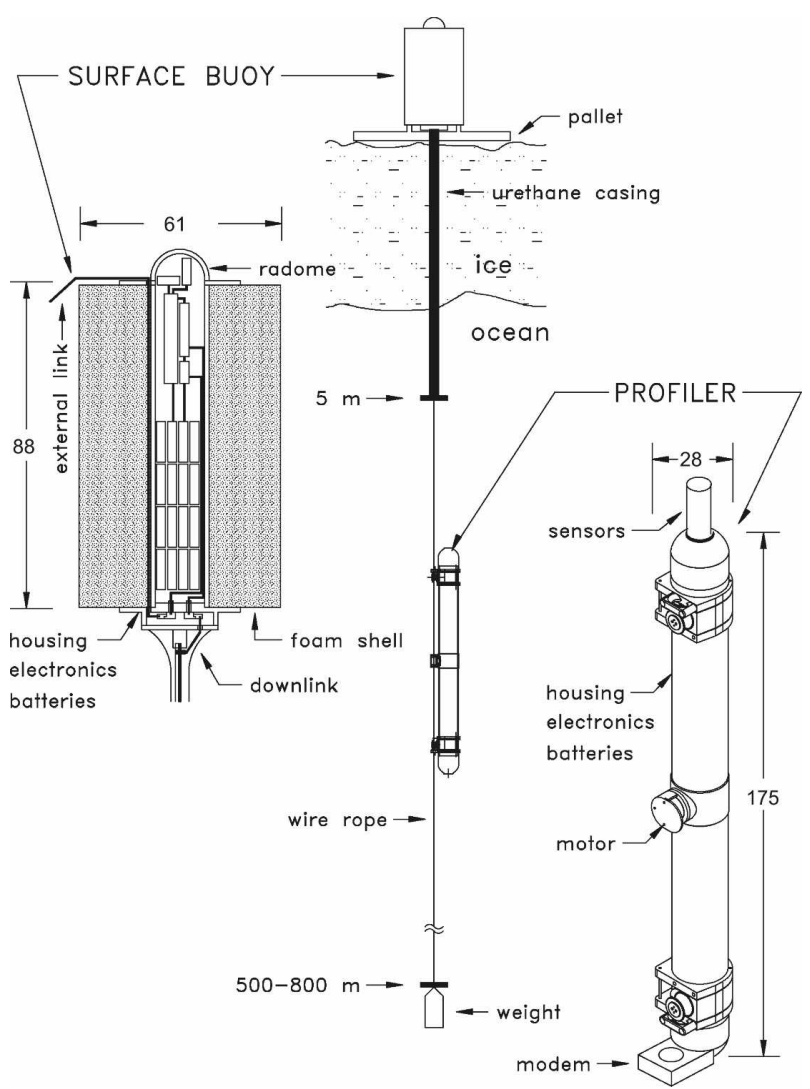

FIG. 1. Ice-Tethered Profiler schematic. Dimensions in cm, except where specified.

\section{Instrument hardware description}

\section{a. Overview}

The ITP system (Fig. 1) consists of three components: a surface instrument package that sits atop an ice floe, a weighted, wire-rope tether of arbitrary length (up to $800 \mathrm{~m}$ ) suspended from the surface package, and an instrumented underwater profiler that travels up and down the wire tether. Hardware specifications are detailed in Table 1. The surface unit houses a controller, a GPS receiver, and data telemetry electronics with associated antennae and batteries. The tether is constructed from conventional plastic-jacketed wire rope. A new variation of the WHOI Moored Profiler (in shape and size much like an Argo float) mounts on the tether and cycles vertically along it. Oceanographic and associated engineering data are transferred from the profiler to the surface controller at the completion of each profile, and then telemetered to shore in near-real time.

The size and weight of the system and the deployment gear were minimized to facilitate handling and transportation. In total, the mass of the ITP hardware is approximately $500 \mathrm{~kg}$, allowing transport to remote sites by a medium lift helicopter or Twin Otter aircraft (along with the deployment technicians, emergency survival gear, and deployment equipment). Several thousand CTD profiles have been returned from the ITPs deployed so far (see section 6), thus supporting the IBO concept as a practical means of making sustained observations of the Arctic air-ice-ocean environment in all seasons.

\section{b. Surface package}

The surface expression of the ITP is a cylindrical buoy that is deployed on a multiyear ice floe. The surface unit incorporates a foam collar for shock absorption to increase the lifetime of the drifter during ridging and, depending on size, may either buoy the system (should the ice fracture) or allow it to sink. (We note that in the former case, it is possible that the surface unit could be crushed between converging ice floes and lost as well.) The 56- or 66-cm outer-diameter surface collar, constructed from Surlyn ionomer foam, surrounds an aluminum electronics compartment $(91 \mathrm{~cm}$ long, $16.5-\mathrm{cm}$ outer-diameter tube) that contains an Iridium modem, GPS receiver, inductive modem interface to the underwater subsystem, data controller, and lithium batteries. The Iridium and GPS antennas are mounted internally on a chassis beneath an ultrahigh molecular-weight polyethylene hemispherical radome, which forms the top endcap. The bottom endcap provides space for penetrators to feed the electrical signals into the compartment and a mount for the tether. Space for an additional bulkhead connector for interfacing with other external sensors is provided, as well as extra tube length for batteries to meet additional power requirements in the future. The yellow surface package is propped on a wooden pallet (assembled during deployment from the shipping crate) to minimize ablation of the ice in contact with the unit. The yellow color was selected as a compromise between white (to minimize solar heating) and orange (for maximum visibility in ice).

The data controller in the surface package (SURFCON) operates the inductive modem interface, obtains the data from the instrument on the subsurface tether, formats the data, and feeds the information to the Iridium satellite transmitter (Fig. 2). The computer at the heart of the controller is the commercially available Persistor CF2, a low-power, C-programmable microcontroller with a $128-\mathrm{Mb}$ compact flashcard memory. The Persistor computer is $1.8 \mathrm{~cm} \times 5 \mathrm{~cm} \times 7.6 \mathrm{~cm}$ in size; both the computer and the flashcard are rated to operate to $-40^{\circ} \mathrm{C}$. The flashcard memory is sufficient to store all acquired instrument and engineering data, status, and 
TABLE 1. Specifications of the ITP hardware and telemetry system.

\begin{tabular}{ll}
\hline \hline Size & Surface unit $-100 \mathrm{~cm}$ in length, $66 \mathrm{~cm}$ in diameter \\
& Underwater profiling unit $-123 \mathrm{~cm}$ in length, $23 \mathrm{~cm}$ in diameter (cylindrical section diameter is $15 \mathrm{~cm}$ ); \\
& fits through $25-\mathrm{cm}$-diameter ice hole \\
& Up to $800 \mathrm{~m}$ \\
Tether length & Surface unit $-70 \mathrm{~kg}$ \\
Mass & Profiler $-30 \mathrm{~kg}$ \\
& Tether $(800 \mathrm{~m})-250 \mathrm{~kg}$ \\
& Termination weight-114 kg \\
& Approximately $1500000 \mathrm{~m}$ on standard battery pack \\
Profiling range & 2.5 to 3 yr returning two $750-\mathrm{m}$ (one way) profiles per day ( 2000 total) \\
Endurance & Operates to $-35^{\circ} \mathrm{C}$ for prototypes, resumes full operation after experiencing temperatures down \\
Surface unit temperature & to $-48^{\circ} \mathrm{C}$ \\
specification & Sea-Bird $41-\mathrm{CP}$ CTD \\
Sensors & Dissolved oxygen, photosynthetically available radiation $(\mathrm{PAR})$, chlorophyll fluorescence, optical \\
& backscatter, and carbonic dissolved organic matter (CDOM) in development \\
& Sea-Bird, Inc., inductive link from profiler to surface unit; \\
Telemetry & Iridium link to shore using dial-up data modem \\
& Typically $50 \mathrm{Kbytes}$ per profile (totaling 100 Mbytes over 3 yr) \\
Data telemetry & Lithium BCX DD battery packs; 3300 Wh in surface package (after derating for temperature) \\
Power & 2500 Wh in profiler \\
&
\end{tabular}

log files for the lifetime of an ITP system. The SURFCON interface board was designed at WHOI to regulate power to the computer, waken upon detecting a tone from the underwater inductive modem (UIM), communicate via the surface inductive modem (SIM), periodically acquire location information from a GPS receiver, control data, and command transmissions with WHOIbased servers via an Iridium satellite link (ISU), provide console access (via an RS232 port), and provide spare logic and RS485 (multidrop) serial ports.

The main serial port is used to program the Persistor and to communicate with the operator via the console access port. The console port is wired to a bulkhead connector on the base of the surface package for access with the battery packs installed and fully assembled. Time processor unit (TPU) channels are configured either as logic $\mathrm{I} / \mathrm{O}$ bits or software serial ports to interface with the tone detector (TD), SIM, Iridium telephone modem, and other serial device ports (logic level, RS232, and RS485). One serial device port on the SURFCON board acquires the GPS data. The other device ports are not presently used but are integrated in the design to support communications to other instruments in the future. The TD board is a product of SeaBird Electronics (product number 41247) and is used to waken the SURFCON board, which in turn applies power to the CF2 computer. Nonvolatile storage allows the computer to resume operation where it left off when suspended. Functionality of each surface controller is laboratory tested to $-48^{\circ} \mathrm{C}$, and though the Iridium unit will not transmit at that temperature, full operations resume after warming with no data loss from the underwater unit.
The commercially available SMODEM-2 SIM (SeaBird Electronics, Inc.) and TD board in the surface unit are electrically connected to the tether conductor, and the tether passes through a corresponding modem toroid that is carried by the profiler. The inductive circuit for communications is completed by grounding plates at each end of the tether conductors and the seawater path. The data link from the SIM to the SURFCON operates at 9600 baud, and the link to the underwater instrument is 1200 baud. Formerly, only ASCII data could be transferred by the SBE modem, but the transmission protocol was upgraded to allow binary data transfers. Firmware changes add a command that allows the SIM to request an 8-bit transfer from the UIM. During the binary transfers, control of the half-duplex link is by a programmable transmission gap at both the SIM and UIM ends rather than by the special characters employed in ASCII transfer. Files of arbitrary length are sent in packets of 4 Kbytes with about a 2-s gap between each; at a nominal 1200 baud, the system achieves a net throughput of approximately 90 bytes $\mathrm{s}^{-1}$. It is worth noting that other devices equipped with inductive modems could also be mounted on the mooring cable (above or below the profiling interval) and configured to communicate with the SURFCON.

The Iridium 9522 L-band transceiver (LBT) modem dials up, logs in, and uploads the profiler data, locations, and status information to a dedicated computer at WHOI. The NAL Research Corporation model A3LA-IG modems on the first prototype ITPs also obtained GPS fixes and that information was added to the instrument data, but a separate GPS receiver is employed on later ITPs (see below). In the ITP applica- 


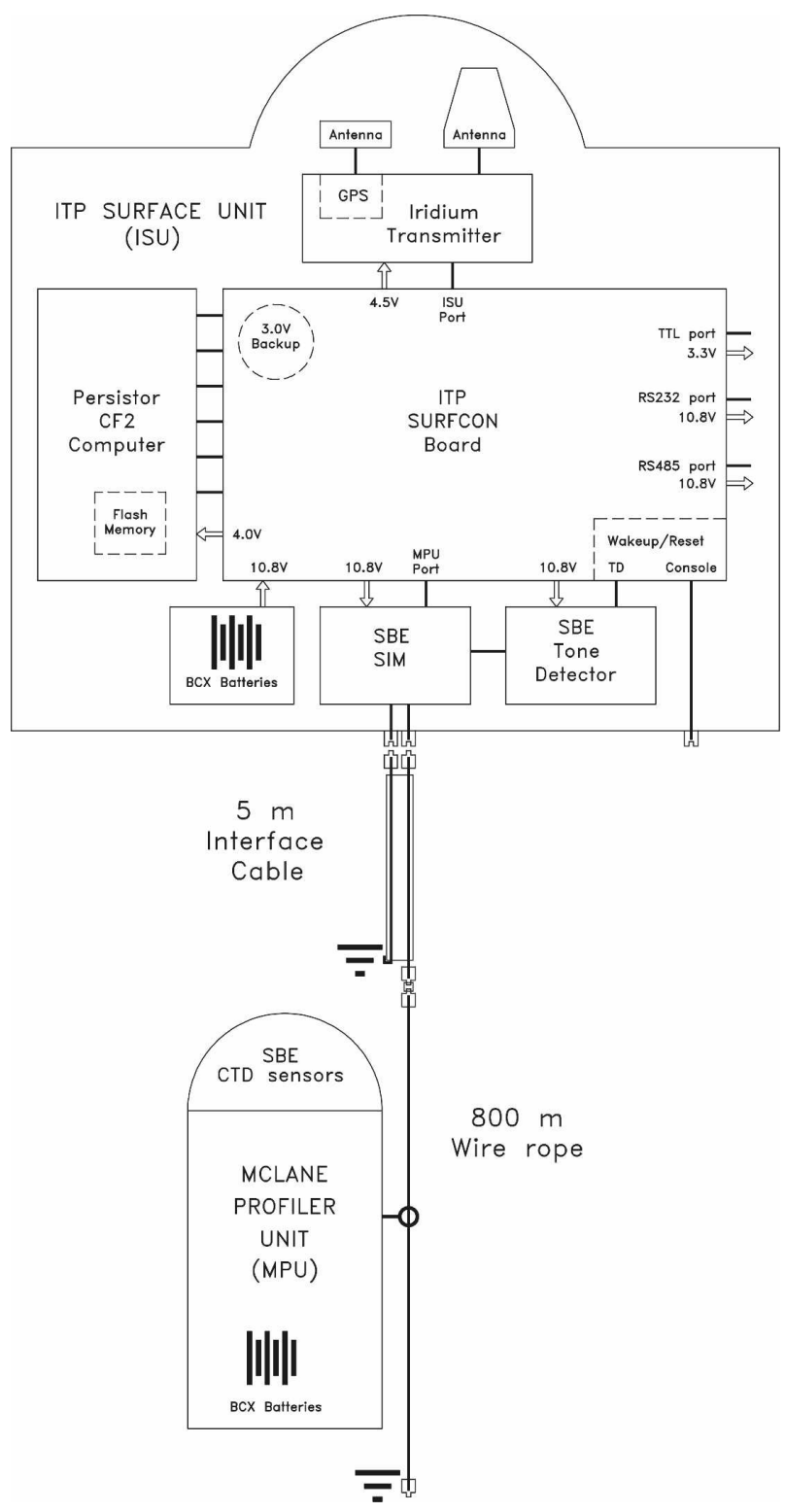

FIG. 2. Block diagram of the ITP electronics subsystems.

tion, the SURFCON powers the modem when it is time to transfer data via Iridium and uses Hayes modem commands over a serial connection to check registration with the Iridium satellite, check signal strength, and dial-up. The Iridium modems (or ISU) that were used on the first prototypes had specified operating temperatures down to $-30^{\circ} \mathrm{C}$, but extended environmental testing of all the surface electronics found some that operated reliably to as cold as $-38^{\circ} \mathrm{C}$. However, the ISUs with integrated GPS needed an increasingly long off period as temperature decreased (as long as 1 $\mathrm{h}$ at $-40^{\circ} \mathrm{C}$ ) to ensure proper functionality at power-up. This did not seem to be a problem on ISUs without integrated GPS; however, the newer Iridium are rated to only $-20^{\circ} \mathrm{C}$ and operate consistently only down to $-28^{\circ} \mathrm{C}$, so periods when data are queued but are not able to be transmitted are more frequent. As noted above, the first three ITPs utilized Iridium modems with integrated GPS receivers. However, because the modems were not equipped with battery backup for the GPS receiver, every location had to be acquired from a cold start: a lengthy process that consumed excessive energy. Consequently, on later ITPs, separate Navman Jupiter 21 GPS receivers are connected to an available logic-level port on the SURFCON board and are provided with a separate backup battery to store locations between acquisitions, thus reducing the time and energy required for a location fix.

\section{c. Tether}

Tethers for ITPs are constructed from standard $0.635-\mathrm{cm}$ plastic-jacketed wire rope with threaded, insulated terminations, providing inexpensive but durable mechanical and electrical connections. The steel wire acts as the electrical conductor for the inductive modem with a seawater return. The upper 5-m segment of the tether is encased in urethane and includes a return wire for the inductive modem circuit that spirals about and is encased with the wire rope. At the top end, the tether threads into a machined fitting that is coupled to the electronics tube and has an electrical breakout connector. The return wire is electrically connected through a similar bulkhead penetrator. At the bottom of the urethane-encased section, the return wire is attached to a grounding plate. The termination at the bottom end of the tether acts as the other grounding plate. Shock-absorbing spring bumpers are clamped onto the wire at the top and bottom of the programmed profiling interval to prevent the ITP from impacting the tether terminations. The tether lengths on the prototype instruments were 790-805 m, but shorter lengths could be used in regions of shallow bathymetry (such as near the 260-m-deep Chukchi Cap). Despite that the ground return wire spirals around the jacketed steel center cable within the urethane-encased section, there is no noticeable effect on the ability of either the SIM or UIM to detect the signal driven by the other over the length of the ITP mooring cable in seawater.

A $114-\mathrm{kg}$ ballast weight (made of $22.7-\mathrm{kg}$ plates to facilitate transportation) is fixed to the bottom wire termination to add tension to the wire and minimize its catenary. The WHOI Cable model (Gobat and Grosenbaugh 2000) was used to determine the attitude of the ITP mooring in response to 25,38 , and $51 \mathrm{~cm} \mathrm{~s}^{-1}$ ice floe drift speeds for several different wire lengths. The model predicts about $5 \mathrm{~m}$ of vertical uplift of the bot- 


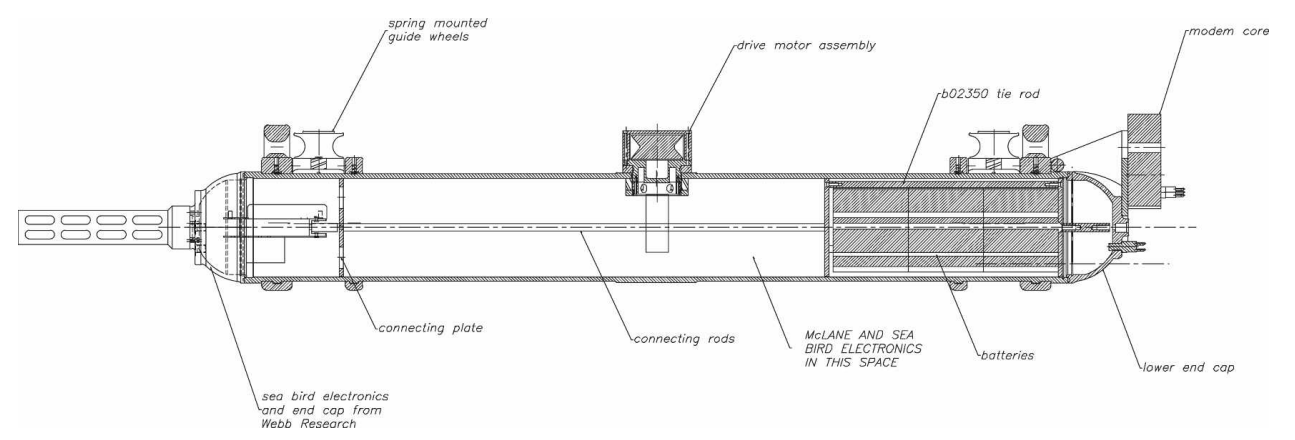

FIG. 3. Detailed schematic of the ITP unit.

tom termination at $25 \mathrm{~cm} \mathrm{~s}^{-1}$, about $32 \mathrm{~m}$ at $38 \mathrm{~cm} \mathrm{~s}^{-1}$, and about $85 \mathrm{~m}$ at $51 \mathrm{~cm} \mathrm{~s}^{-1}$. Horizontal displacement of the bottom termination is indicated to be about 100 , 220 , and $350 \mathrm{~m}$, respectively. To accommodate the catenary of the ITP mooring at times of ice floe drift speeds of up to $35 \mathrm{~cm} \mathrm{~s}^{-1}, 25$ or $30 \mathrm{~m}$ of extra cable (beyond the programmed maximum profiling depth) is needed; mooring cables of about a 790-m length allow for profiles as deep as $760 \mathrm{~m}$ in the vast majority of ice drift conditions. In extreme cases when drift rates approach $50 \mathrm{~cm} \mathrm{~s}^{-1}$, it may be impossible for the profiler to climb the wire against the current, making moot the depth of the tether bottom bumper.

\section{d. Profiler}

The cylindrical pressure case of the profiler unit (Fig. 3 ) houses the batteries, drive system, instrument controller (PROCON), CTD, and UIM, as well as provides buoyancy for the unit. The PROCON hardware (a Tattletale 8 micrologger from Onset Computer with a $512-\mathrm{Mb}$ flashcard memory) and software were acquired from McLane Research Laboratories, Inc. (MRL): elements are based on the commercially available McLane Moored Profiler (MMP; Morrison et al. 2000). ITPs are equipped with the SBE-41CP CTD sensor (manufactured by Sea-Bird Electronics, Inc.) mounted in the top hemispherical endcap on the cylindrical pressure case. Consequently, down-profile measurements may be influenced by the wake of the instrument (as opposed to lowered CTDs, which typically have their sensors mounted on the bottom, so are subject to the influences of instrument wake on the upcast). At the opposite end of the pressure case, a split-core modem toroid is mounted and electrically connected to the UIM electronics through a bulkhead connector in the lower hemispherical endcap.

The low-power CTD (drawing about $0.25 \mathrm{~W}$ in continuous operation) samples at $1 \mathrm{~Hz}$ while profiling in either direction, although data from the downgoing profiles can be degraded at times by the wake of the
ITP body. Wake errors in downgoing profiles largely depend on the strength of the ice-water velocity difference in comparison to the profile speed (dictating the shape of the instrument wake relative to the CTD sensing volume). Data from the first prototype ITPs indicate obvious smoothing of temperature and salinity fine structure in the down profiles versus the up-profiles when ice floe drift speeds are less than $\sim 15 \mathrm{~cm} \mathrm{~s}^{-1}$. With the relatively fast data rate of the Iridium link, we are able send the full $1-\mathrm{Hz}$ sample-rate CTD data to shore. High-resolution sampling will facilitate study of double-diffusive layering, intrusions, and other finescale structure. Johnson et al. (2007) exploited observations of layered stratification to quantify the response characteristics of the SBE-41CP CTD. Though the basic ITP system samples only temperature and conductivity versus pressure, the hardware can support other onboard sensors (such as dissolved oxygen, bio-optical sensors, and a current meter).

To facilitate deployment of the device, the ITP was designed so that it can be deployed through a $28-\mathrm{cm}$ hole in the ice floe (the practical maximum diameter that can be bored using conventional hand augers). The $16.5-\mathrm{cm}$-diameter cylindrical pressure case facilitates this requirement. Rather than use the pumped, variable buoyancy system of the Argo float and POPS (Kikuchi et al. 2007), a traction drive unit (very similar to that used on the MP) is mounted roughly midway along the profiler's pressure case. As opposed to existing variable buoyancy systems, the traction drive can develop greater force and thus is better able to function in strong currents with large wire angles or overcome obstructions on the wire. Torque from a small brush-type motor running in air within the pressure case is transferred with a magnetic coupler to the drive wheel in the seawater. The motor control is a closed loop system so that when voltage is applied, the motor speed and current drain depend on the load. If major obstructions on the wire or excessive hydrodynamic resistance caused by rapid mooring drift (discussed further in section $6 \mathrm{a}$ ) 
are encountered, the motor drive magnetically decouples, reducing current drain. In these cases, the control logic will attempt to resume profiling 5 times before ceasing operations until the next scheduled profile time. The wheel is held in tension against the wire by two spring-loaded guide sheaves at the top and bottom of the profiler. To hold position between profiles, the drive motor leads are shorted; the induced electromagnetic field (emf) associated with motion of the drive wheel serves as a dynamic brake. The ITPs are nominally ballasted to be neutrally buoyant near the midpoint of their profiling range. Modest errors in ballasting incur no penalty in performance as the additional energy needed to work against buoyancy in one profile direction is recouped in the other direction. The power requirement of the ITP drive system is approximately 1 $\mathrm{W}$ to profile at the nominal speed of $25 \mathrm{~cm} \mathrm{~s}^{-1}$.

\section{e. Power}

Separate battery packs consisting of multiple lithium BCX DD battery slices power both the surface unit and the underwater profiler. For interchangeability and convenience, the same battery slice design was used in both units. Each 12-cell 10.8-V battery slice consists of three cells wired in a series with a diode and four series wired in parallel, and each nominally provides $1250 \mathrm{Wh}$ of power. A 3-A fuse protects each slice against damage due to accidental short circuiting during installation in the instrument. Based on the operation of prototype ITPs in the field, a total of three slices (36 batteries) should be capable of powering the surface electronics for over $4 \mathrm{yr}$ at two profiles per day (after derating the batteries to account for cold temperature degradation), while two slices ( 24 cells) should sustain the underwater profiler for over $2.5 \mathrm{yr}$ at this sampling rate.

While the SURFCON circuit board has connectors to accommodate as many as six slices, the present tube length of the surface buoy limits capacity to four slices. Three slices together should produce at least $3300 \mathrm{Wh}$ after derating for temperature. The supply voltage is regulated to $4.0 \mathrm{~V}$ for the $\mathrm{CF} 2$, and $4.5 \mathrm{~V}$ for the ISU. A 3-V backup battery for the CF2 is also included. During operation, current drain is typically less than $120 \mu \mathrm{A}$ in sleep mode (almost entirely from the TD board), while the interface board draws $10 \mu \mathrm{A}$ from its backup battery. Based on a data throughput of 100 Kbytes day ${ }^{-1}$ from the profiler (two profiles), 100 bytes $\mathrm{s}^{-1}$ inductive modem link, and 200 bytes $\mathrm{s}^{-1}$ Iridium link, the power requirements of the surface unit are estimated to be less than $2 \mathrm{Wh}_{\text {day }}{ }^{-1}$.

The profiler battery pack consists of two slices totaling $2500 \mathrm{Wh}$ (derated for temperature), sufficient for an estimated system endurance of 1.5 million meters of profiling based on a total energy consumption rate of $1.35 \mathrm{~W}$ during profiling operations. The PROCON electrical drain in sleep mode is negligible. Consequently, with a standard battery pack, ITPs scheduled to profile twice per day are expected to have sufficient power to last for at least $2.5 \mathrm{yr}$. Furthermore, there is sufficient room in the profiler tube (and instrument buoyancy) for an additional 1250-Wh battery, which would increase the instrument endurance by $50 \%$.

\section{Software operation}

\section{a. SURFCON}

In operation, the ITP SURFCON acquires technical status information along with position and time data from the GPS, controls the surface inductive modem interface to communicate with the underwater inductive modem on the profiler, obtains the data from the PROCON, and feeds the information to the Iridium satellite unit. The SURFCON activities are controlled by an operations program written to accommodate all known instrument states, but a hardware watchdog timer is included to increase the likelihood of recovery from stalled states or a genuine processor problem. The watchdog causes the CF-2 operating system to restart after 20 min of inactivity. Upon power-up (or reset), the Persistor CF- 2 controller begins running the ITP operation program indicated in its AUTOEXEC.BAT file. After initializing the hardware, loading the operating variables (by reading a configuration file), and opening a log file to record operating events, the program enters the main operations loop, which responds to interrupts from the tone detector to receive data from the profiler and keeps two separate schedules: one for obtaining engineering status and GPS location information and one for telemetering queued data files via Iridium.

Between these scheduled operations, SURFCON reverts to what is essentially a power-off condition in which only the real-time clock and main memory are supported while drawing only $10 \mu \mathrm{A}$. SURFCON awakens from this suspended condition for two reasons: 1) time, when either the next status check or time to conduct ISU operations has been reached, and 2) tone detection, generated by the UIM or RESET switch. At status check time, the SURFCON saves the GPS location, internal buoy temperature, and battery voltage information in status and log files. When the tone detector signals, SURFCON awakens and enters a program branch to conduct inductive modem communications. Briefly, SURFCON sequentially prompts the PROCON to respond with the name of each new pro- 
filer file to be relayed, the file, and check-sum information. This process repeats until all the new files in the profiler queue are transferred to SURFCON, which subsequently stores the files in subdirectories by year and adds the file names to the transmission queue. At times of scheduled Iridium uploads, SURFCON reads file names from the queue, powers, and registers the ISU, dials the WHOI data-serving computer, sends all files in the queue, receives any user commands that may have been issued, then terminates the call. At the present time, the commands are limited to specific file retransmission requests and directory listings from either the SURFCON or PROCON. Files remain in the transmission queue until they have been successfully relayed to shore; SURFCON attempts Iridium data transfer every $4 \mathrm{~h}$ until the queue is empty. The scheduled telemetry times for the ITPs are staggered so that systems do not collide when trying to place calls to the laboratory data servers.

\section{b. PROCON}

The PROCON operating system is based on the standard MMP operating software (see Morrison et al. 2000 for details) adapted by MRL for the ITP application to support inductive modem communications. The system acquires profiles based on user-programmable sampling depths and schedule, either in regular (evenly spaced) or burst sampling modes. At the end of each one-way profile, PROCON downloads data from the CTD into one file, formats engineering information into a second file, and relays both via the Sea-Bird SBE-44 UIM to the SURFCON. Should the inductive modem link be interrupted for periods of time, all available files not yet transmitted will be sent to the SURFCON upon restoration of modem function. The PROCON software allows for all or a limited revolving number of profiles to be saved on the flash memory card.

A limitation of the file allocation in the PROCON operating system dictates that a maximum of about 2042 profiles (two files per profile) may be saved in the root directory. Deployments that are planned to acquire more than this number of profiles must activate the protocol for revolving deletion of old files. The battery capacity of the profiler with a standard pack is expected to allow approximately 2000 (750 m long) profiles, so normally this software limitation will not be reached. However, because ITPs are not expected to be recovered, the PROCON is usually configured for file deletion after each profile (retaining on the flash memory card data from only the most recent 40 profiles). Note that PROCON only allows the deletion of files that have been successfully transmitted to SURFCON.

\section{c. Shore-based data acquisition, display, and distribution system}

To receive the ITP data uploads, two logger computers running Linux are connected by a Rev 2 Hayes modem to dedicated telephone lines at WHOI. The logger computers are configured for binary data acquisition and can handle partial file transfers (due to Iridium link loss) by instructing SURFCON to retransmit incomplete files starting after the last correct packet received by the logger. This entails switching the master-slave responsibilities in the protocol such that once a call connects, SURFCON prompts the logger. The expected response is a request to either restart a failed transmission, transmit a new file (most often the case), or receive a command packet.

SURFCON normally sends two files per profile (an engineering file, about 20 Kbytes, and a CTD data file, about 30 Kbytes), in addition to a daily ( $\sim 4$ Kbyte) status file. When SURFCON sends a file via Iridium to the logger computer at WHOI, it is done in 2048-byte packets, each with a similar header. If a packet is received correctly, the logger strips off the header bytes and appends to the current file. CTD and engineering files from SURFCON are sent to the logger, preceded by a 50-character PROCON metastructure and appended with a 70-character SURFCON metastructure. The two structures are identical for the first 49 characters to ensure that the description source of each file is embedded in that file and likely recoverable should file names become corrupted somehow.

All of the telemetered data are processed and made publicly available under the "Data" heading on the ITP Internet Web site (http://www.whoi.edu/itp) as soon as they are received. Within $2 \mathrm{~h}$ after arriving on the WHOI logger computer, the files from each profile are accessed by a separate computer that acquires the binary data files from the logger computer, extracts and performs a rudimentary editing of the data, binaverages the CTD data into convenient 1 - or 2-db pressure bins, produces plots, and saves the data in ASCII and MATLAB format files. These binned data (termed our Level 2 product) as well as the raw CTD and engineering data from each profile (Level 1 product) are immediately made available through the ITP Internet site, along with the raw GPS buoy location data in an ASCII file. The raw locations provided on the Web site are not screened to remove spurious glitches, but the location time series are filtered and interpolated to produce location information for each pressure-binaveraged profile data file. We recently finalized a procedure to produce response-corrected, calibrated, edited, pressure-binned profile data following methods 
TABLE 2. ITP installation dates and longevity.

\begin{tabular}{|c|c|c|c|c|c|c|c|}
\hline & Deployment & Last location & Last profile & $\begin{array}{l}\text { Profiles } \\
\text { per day }\end{array}$ & $\begin{array}{c}\text { Duration } \\
\text { (days) }\end{array}$ & $\begin{array}{c}\text { Drift } \\
\text { distance } \\
(\mathrm{km})\end{array}$ & $\begin{array}{l}\text { No. of } \\
\text { profiles }\end{array}$ \\
\hline ITP2 & 19 Aug 2004 & 28 Sep 2004 & 29 Sep 2004 & 6 & 40 & 374 & 244 \\
\hline ITP1 & 15 Aug 2005 & Recovered 8 Aug 2007 & 8 Jan 2007 & 4 & 723 & 4990 & 2043 \\
\hline ITP3 & 23 Aug 2005 & 9 Sep 2006 & 10 Sep 2006 & 4 & 382 & 2559 & 1532 \\
\hline ITP4 & 3 Sep 2006 & Recovered 17 Aug 2007 & 17 Aug 2007 & 2 & 349 & 2485 & 698 \\
\hline ITP6 & 4 Sep 2006 & 13 Jan 2008 & 21 Jan 2008 & 2 & 503 & 3925 & 1008 \\
\hline ITP5 & 7 Sep 2006 & 1 Dec 2007 & 7 Sep 2007 & 3 & 453 & 3892 & 1095 \\
\hline
\end{tabular}

developed to treat MMP and Argo float data. These Level 3 data are also being made publicly available on the ITP Web site as well as offered or delivered to the national data archives, including International Arctic Buoy Program (IABP), National Snow and Ice Data Center (NSIDC), National Oceanographic Data Center (NODC), GODAE, and Arctic Observing Network (AON). A full description of the processing procedures will be available on the ITP Web site.

\section{Installation procedures}

The ITP system is designed so that it may be deployed directly from an icebreaker using man hauling or helicopter ferrying, or up to 300 miles from fuel depots using a single small aircraft (Newhall et al. 2007). This is achieved by minimizing the size and weight of the system and the deployment gear; the mass of an ITP system totals approximately $500 \mathrm{~kg}(1100 \mathrm{lb})$. Deployment equipment brings the total mass up to $1100 \mathrm{~kg}(2400 \mathrm{lb})$. This weight may be transported by a medium lift helicopter (such as the Bell 212), larger Russian MI-8s, or by the DeHavilland Twin Otter airplane. Of course, the amount of equipment that can be transported to a deployment site during any single flight is a function of the distance of the base of operations. If the round-trip distance is reduced, several ITP systems could be loaded onto and deployed from a single Twin Otter. When employing smaller aircraft, multiple lifts of equipment and personnel are required to stage and return from a deployment.

Reconnaissance flights to select appropriate ice floes typically include one to two technicians (in addition to the pilot and a rifle bearer) with a 2-in. hand auger and measuring tape. Multiyear ice floes are identified, landed upon, and drilled to determine ice thickness. The ideal platform for an ITP deployment is a multiyear ice floe that is relatively thick $(2.5-4.5 \mathrm{~m})$, level, and sparsely ponded. If possible, the surface float is positioned on a hummock or slight rise in the ice surface, but solar heating of the buoy typically causes a melt pond to form around the float during summer. For the deployment operation, two to three technicians (plus pilot and rifle bearer) and the entire complement of the gear $(1100 \mathrm{~kg})$ must be transported to the selected site. Each ITP system is transported to the deployment site in four main pieces: surface package, wire tether on an aluminum spool, anchor weight, and the profiler unit.

Upon arrival at the site, and with the aid of a lightweight, portable tripod, the tether ballast weight and subsurface tether are deployed through a $\sim 28-\mathrm{cm}-$ diameter hole augered through the ice floe. At a convenient point, the ITP is mounted on the wire (using two bracket connections) and eased down the wire through the ice hole. After making one mechanical and electrical connection at the surface unit, the package is positioned onto a wooden palette over the hole and the tripod is disassembled. Based on the preprogrammed sampling plan entered in the ITP profiler, the instrument will then start working.

Once everything was assembled on the target ice floes, the operations to deploy the prototype ITPs took between 2 and $4 \mathrm{~h}$. Including the two-way transportation time, a full ITP system may be deployed in 4-8 h.

\section{Performance of ITPs}

Six ITPs were deployed prior to 2007 (Table 2). One ITP (serial number 2) was deployed in 2004, two in 2005 ( 1 and 3), and three in 2006 (4, 5, and 6), all in conjunction with Joint Western Arctic Climate Study (JWACS) expeditions on the CCGS Louis S. St. Laurent (Fig. 4). Five of the systems were installed utilizing small helicopter transport; ITP 3 was deployed by lowering equipment over the side of the icebreaker and man hauling it into position. The first three ITPs were prototypes, deployed during our instrument development period. They were programmed with frequent profiling schedules (four to six one-way profiles per day). The three units that were deployed in 2006 have fundamentally the same hardware as the prototypes (with updated software) but are programmed with a less frequent sampling schedule to obtain observations 


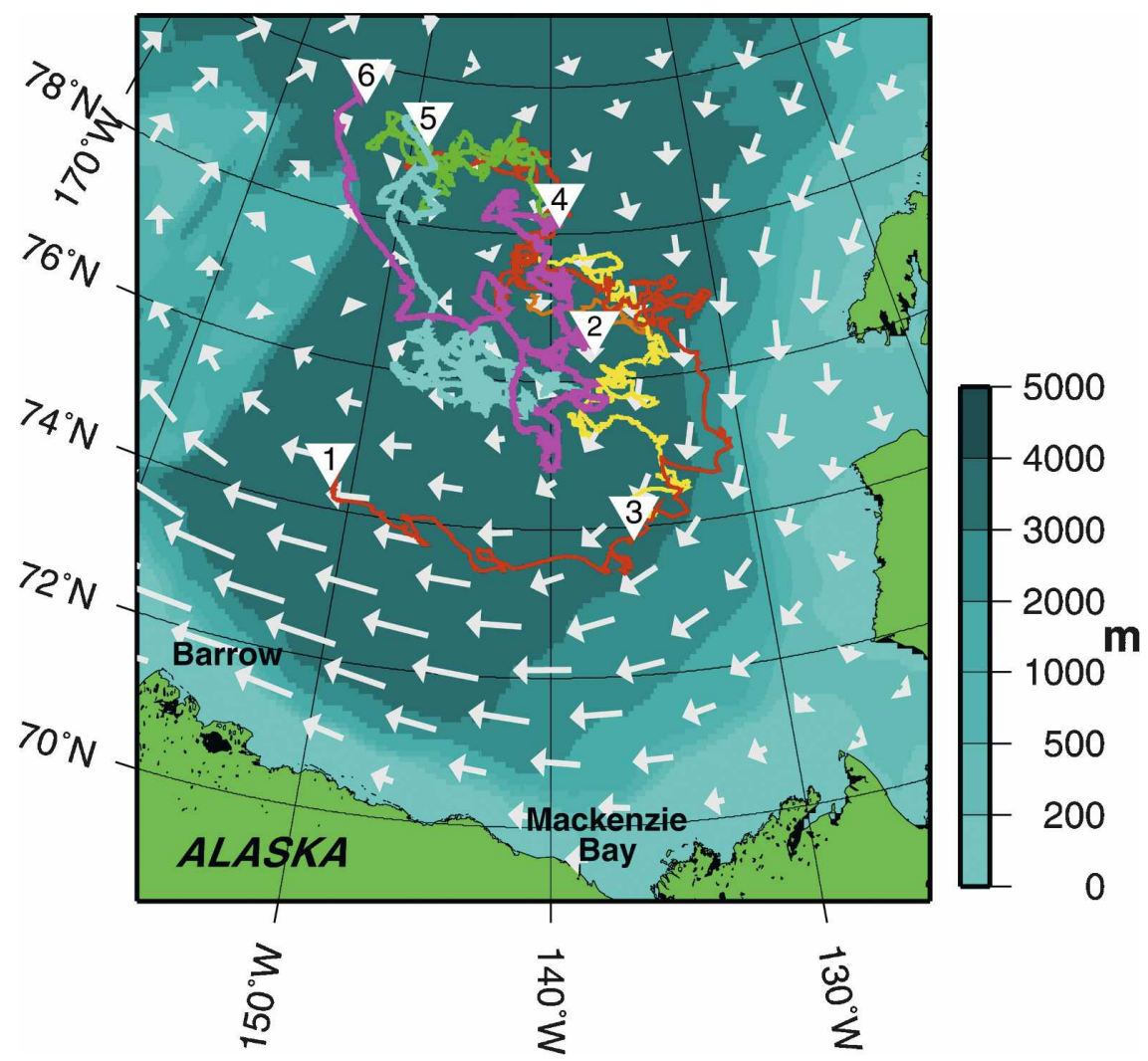

FIG. 4. ITP drift tracks in Canada Basin (as of January 2008): ITP2 in 2004 (orange); ITP1 (red) and ITP3 (yellow) in 2005; ITP4 (green), ITP5 (cyan), and ITP6 (violet) in 2006. Numbers mark last locations. Climatological ice drift vectors from the International Arctic Buoy Program (http://iabp.apl.washington.edu/) are gray arrows superimposed on shaded bathymetry.

over a longer duration as part of an ITP/IBO array contributing to the AON.

ITP 2 was deployed in the Beaufort Sea on 19 August 2004 at $77.174^{\circ} \mathrm{N}, 141.238^{\circ} \mathrm{W}$ during the $2004 \mathrm{JWACS}$ expedition. ITP 2 and an IMB, developed by the Cold Regions Research and Engineering Laboratory (number 07413), were deployed on a 4-m-thick multiyear ice floe. ITP 2 collected 244 profiles on a fast sample schedule of six one-way profiles between 10- and 750-m depth each day, but it ceased communicating to the shore station unexpectedly. The demise of ITP 2 due to electronics failure is a possibility, but the last telemetered measurements of battery voltages and other engineering information gave no indication of impending failure. On the other hand, the bottom half of the ice floe on which the ITP was positioned was relatively porous; we cannot rule out that the floe fractured and ITP 2 sank. Despite the abbreviated lifetime of the first system, the ITP technology was proven to function, and the acquired data was of high quality.

In 2005, some significant changes were made to the software in both the SURFCON and PROCON units to eliminate potential problems that were identified in the first prototype, and two more prototype systems were deployed in the Beaufort Sea during the JWACS 2005 expedition. ITP 1 was deployed on 15 August 2005 at $78^{\circ} 51.1^{\prime} \mathrm{N}, 150^{\circ} 15.9^{\prime} \mathrm{W}$ with IMB 07949 on a $4.6-\mathrm{m}$-thick multiyear ice floe, and ITP 3 was deployed on $23 \mathrm{Au}$ gust 2005 at $77^{\circ} 36.1^{\prime} \mathrm{N}, 142^{\circ} 11.8^{\prime} \mathrm{W}$ (about $200 \mathrm{~km}$ to the west of ITP 1) with IMB 07950 on a 3.5 -m-thick multiyear ice floe. Both ITP 1 and ITP 3 operated on a fast sample schedule of four one-way profiles between 10- and 760-m depth each day. ITP 1 was outfitted with an extra battery slice in both the profiler and surface package to supply $50 \%$ more power than available from the standard packs.

As expected from our electrical power budget estimates, ITP 3 acquired 1532 profiles (over a 13-month span due to its accelerated sample schedule) before the battery voltage in the profiler unit began to drop precipitously. An attempt was made to recover the unit during the JWACS 2006 expedition but, unfortunately, the floe that contained that unit was too small, too thick, and too uneven for a straightforward recovery; 

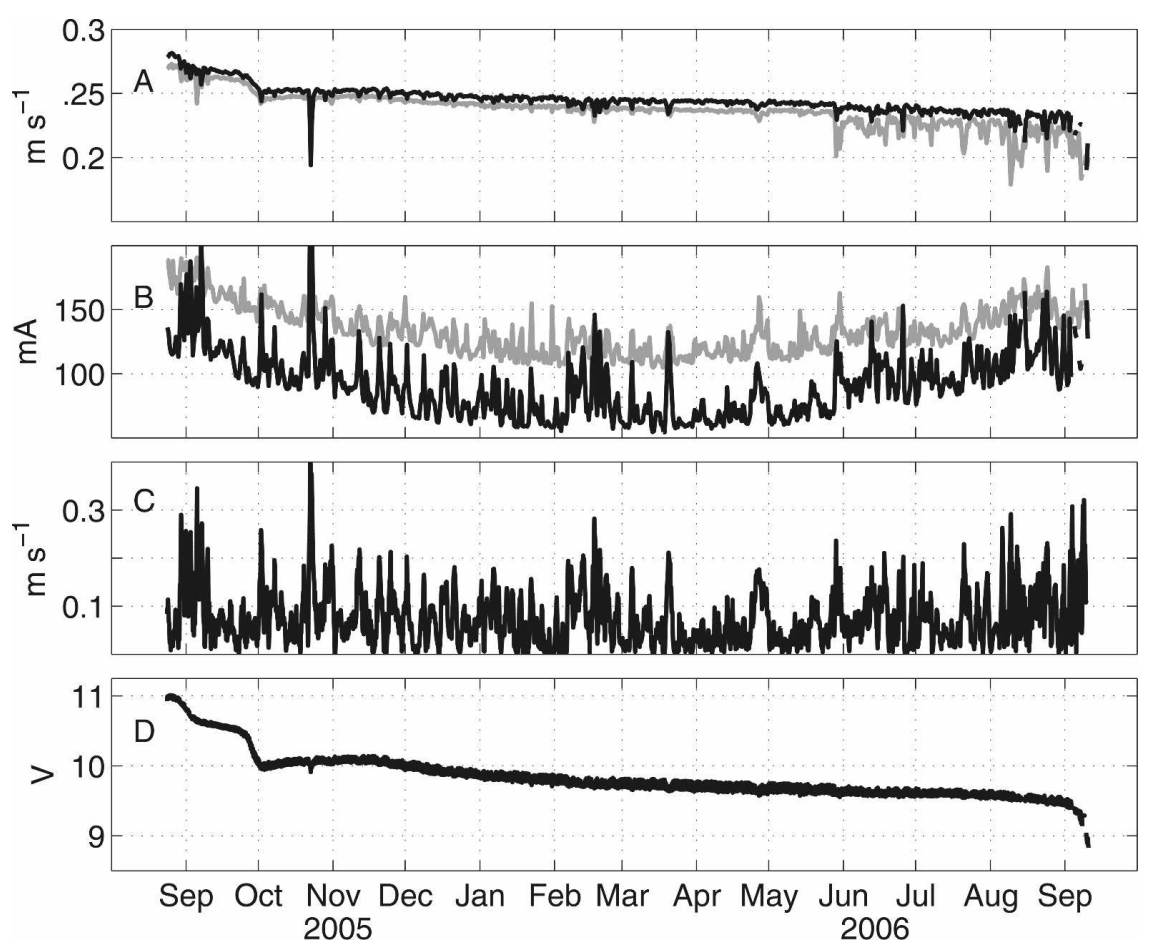

FIG. 5. Time series of engineering data from ITP 3 for the duration of the instrument's operational life. Displayed are data averaged over the pressure interval from 50 to $700 \mathrm{db}$. Where two curves are shown, data from upgoing runs are indicated in black, downgoing runs in gray. (a) Profile speed, (bB) motor current, (c) ice-floe drift speed, and (d) battery voltage.

instead, the instrument was destroyed in the process. ITP 1 acquired 2042 profiles (over a 17-month span) before a software limitation (since removed) caused the profiler to cease profiling. However, the surface package of ITP 1 continued to broadcast the location and engineering information from SURFCON, and the unit was recovered in August 2007. The duration of these systems confirmed the design specification that approximately 1.5 million profiling meters can be accomplished with a standard battery, which at two profiles per day, translates to a lifetime of nearly $3 \mathrm{yr}$.

Three more ITPs were deployed in the Beaufort Sea during the 2006 JWACS expedition. ITP 4 and ITP 5 carried the standard SBE CTD sensor, while ITP 6 included an SBE-43 dissolved oxygen sensor developed for the Argo float program. A problem with the inductive modem circuit on ITP 4 prevented relay of any of the profiler data to the surface unit, but these data $(698$ profiles) were retrieved from the underwater profiler when that unit was also recovered in August 2007. Further building on the IBO concept, ITP 6 was deployed in conjunction with an IMB and a Naval Postgraduate School heat flux buoy (AOFB), all of which were encircled by an International Arctic Research Center GPS ice drift/deformation array.

\section{Sample data from prototype ITPs}

\section{a. Instrument performance}

Our ballasting procedures appear to result in the ITPs being neutrally buoyant around $100-150-\mathrm{m}$ depth: somewhat shallower than the target middepth of $375 \mathrm{~m}$. (During times of weak ice motion, observed upgoing and downgoing motor currents are comparable about this depth.) Fortuitously, this bias from the midsampledepth level may facilitate profiling at times of large ice floe motion (see below). ITP profiling speeds of 25-28 $\mathrm{cm} \mathrm{s}^{-1}$ are roughly proportional to battery voltage and are achieved with profile-averaged motor current from the $10-11-\mathrm{V}$ battery supply ranging between 50 and 300 $\mathrm{mA}$ (Fig. 5). Larger motor currents are observed at times of fast ice floe motion when we presume that drag on the profiler and wire is increased. Typically, the profile-mean motor current is around $150 \mathrm{~mA}$ early in a deployment but falls to around or below $100 \mathrm{~mA}$ after $\sim 100$ profiles when drive system components presumably pass a break-in period. When the ice velocity approaches $50 \mathrm{~cm} \mathrm{~s}^{-1}$, we observe that profilers have trouble climbing the inclined tether against the relative current, and at such times only partial profiles are occupied. In the Beaufort Sea region, these times are rare: 

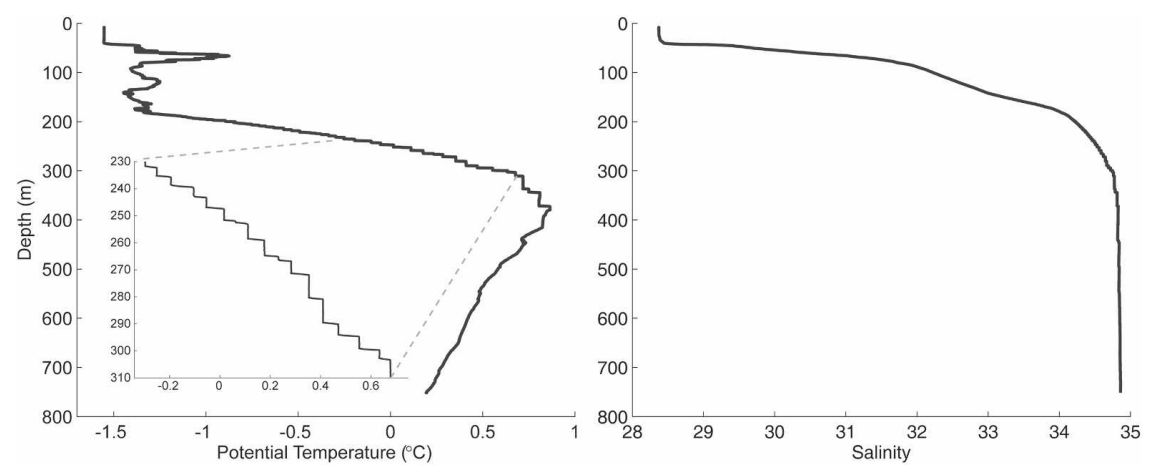

FIG. 6. Profiles of potential temperature and salinity (ITP 6,8 Jan $2007,77^{\circ} \mathrm{N}, 140^{\circ} \mathrm{W}$ ). The inset with expanded scales shows a double-diffusive staircase. In this profile, the Arctic surface mixed layer extends to about 40-m depth, with shelf-modified Pacific Water from the Bering Strait immediately below. A strong thermocline denotes the boundary between the upper waters and the Atlantic Layer. Within the thermocline, temperature (and salinity) increases monotonically with depth, a necessary condition for double-diffusive layering. The ITP can resolve individual mixed layers and the interface gradients between them as thin as $25 \mathrm{~cm}$.

fewer than $4 \%$ of the scheduled profiles attempted by ITPs 1 through 6 (6620 total as of January 2008) failed to sample at least $700 \mathrm{~m}$ of the water column, and less than $1 \%$ (only 41 profiles total) sampled less than $10 \mathrm{~m}$ of the water column.

The voltage provided by BCX DD batteries varies only weakly as energy is extracted. We observe a characteristic initial drop in battery pack voltage from $\sim 11$ to $\sim 10 \mathrm{~V}$ during the first $10 \%$ of a mission, followed by an extended period during which the supply voltage slowly falls to $9.5 \mathrm{~V}$. Very near end of life, the battery pack voltage drops sharply; the PROCON operations program terminates profiling when the supply falls below $8.5 \mathrm{~V}$.

The CTD sensors deployed on ITPs have been relatively robust, but there have been rare instances of short-term sensor contamination, presumably associated with biofouling. Rather than something growing on or in the CTD sensor, these appear to be cases of foreign material being ingested by the CTD and subsequently cleared one or two profiles later. It is possible that some of these fouling events in winter were caused by ingestion of ice crystals near the surface, but the vast majority of fouling events occurred or extended to depths where the in situ temperatures were well above freezing. Profile segments with seriously fouled conductivity are removed during final data processing. The temperature sensors appear to be less sensitive to fouling than the conductivity sensors; only $0.3 \%$ of the temperature profiles had identifiable segments of corrupted data versus $2.6 \%$ for conductivity. No temperature profiles were completely corrupted, but $0.6 \%$ of the conductivity profiles were. At times, these fouling events induce shifts of the conductivity sensor calibration and changes in the temporal response characteris- tics of the instrument. Overall conductivity sensor stability has been quite good; potential temperaturesalinity data from 500-700-m depth for a given instrument typically show a 0.1 spread in salinity (excluding fouled profiles), some of which is believed to be real spatial water property variability. One aspect of our processing scheme is the derivation of in situ conductivity adjustments by referencing to regional (calibrated) ship hydrographic data.

As discussed previously, the Iridium modems do not operate in extreme cold temperatures. For the older ITP modems, which have temperature limits approaching $-38^{\circ} \mathrm{C}$, we estimate that this behavior delayed data transmission only $4 \%$ of the time for ITP 3 and not at all for ITPs 1 and 2. For the newer modems on ITPs 4 and 5 (with temperature thresholds of approximately $-28^{\circ} \mathrm{C}$ ) we estimate that data transmissions were delayed $12 \%-15 \%$ of the time (only during winter months). Regardless, all stored data were subsequently transferred after the modem warmed. At one point, ITP6 transmissions and GPS positioning were either fully or partially obstructed for over a month beginning at the end of the melt season (when it is likely that system was in a ridge or pushed below an floe), but the system recovered and transmitted all stored data.

Data provided by the ITP prototypes indicate that the GPS location data suffers from occasional spikes in latitude, independent of the GPS receiver used. During laboratory testing with a fixed antenna, the magnitude of the spikes typically exceeds $1 \mathrm{~km}$. In the field, the erroneous latitudes comprise between $10 \%-12 \%$ of the record and are easily identified with a low-pass, firstdifference filter and removed. We are still trying to determine the cause of the latitude spikes. 


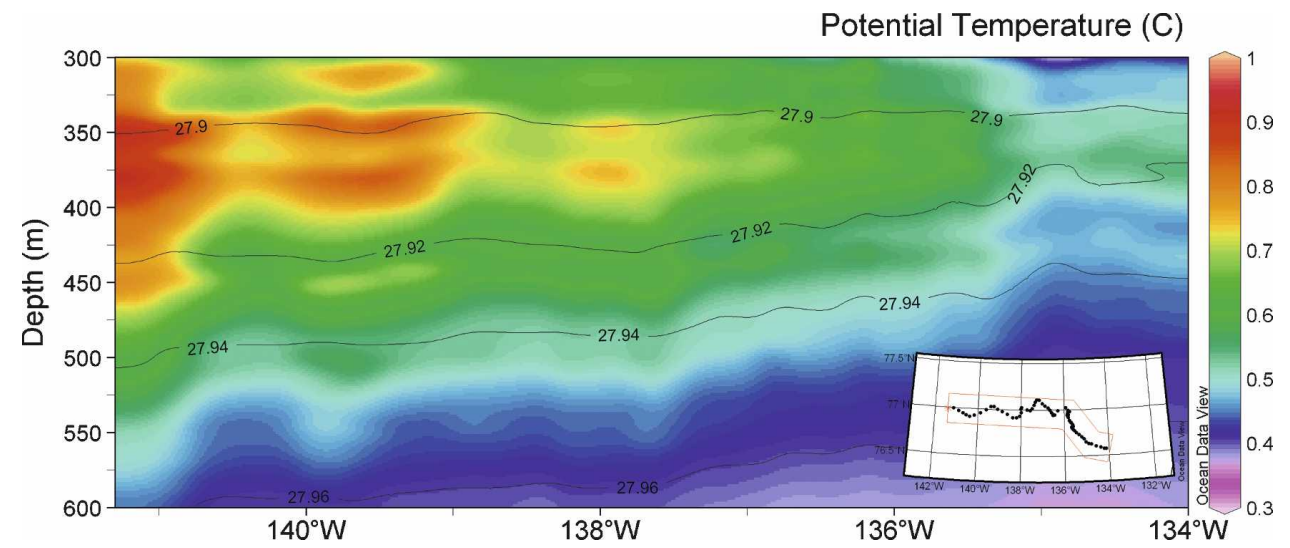

FIG. 7. ITP 2 potential temperature section, where lines of constant potential density (referenced to the surface) are also shown (similarly, in Figs. 8, 9). Note ITP drift speeds $\left(10-30 \mathrm{~cm} \mathrm{~s}^{-1}\right)$ are much faster than typical surface currents $\left(0-2 \mathrm{~cm} \mathrm{~s}^{-1}\right)$. The warm Atlantic Layer $(350-400 \mathrm{~m})$ front is clearly seen at about $137^{\circ} \mathrm{W}$. Horizontal resolution is better than $2.5 \mathrm{~km}$.

\section{b. Observed ocean features}

The CTD profiles obtained so far document interesting spatial variations in the major water masses of the Canada Basin, including the low-salinity surface mixed layer; the complex forming the Pacific Halocline Waters, characterized by multiple temperature extrema between 40- and 180-m depth indicative of the Alaska Coastal Water; the summer and winter Bering Strait Water and winter shelf waters emanating from Barrow and possibly Herald Canyons; and the temperature maximum around 350-m depth, characterizing the Atlantic Water (Figs. 6, 7). Additionally, the recovered $1-\mathrm{Hz}$ CTD data resolve fairly well the thermohaline staircase stratification above the Atlantic Layer, thought to be caused by double diffusion (Fig. 6, inset) and the "nested" intrusive structures that incise the Atlantic Layer.

The ITP data also provide a detailed view of the spatial distribution of fronts (e.g., Fig. 7), seasonal changes in the mixed layer (Fig. 8), and warm and cold core eddies (Fig. 9). In particular, 21 anticyclonic cold core eddies centered between 42- and 69-m depth were identified in the central Canada Basin and shown to be consistent with formation by instability of a surface front at about $80^{\circ} \mathrm{N}$ (Timmermans et al. 2008). Meanwhile a deeper and much thicker Atlantic Layer eddy was apparently crossed twice in August 2005 by ITP 1 (Toole et al. 2006). Few observations exist of these deeper features throughout the Arctic Ocean.

\section{Current and future plans}

The practical, cost-effective, and proven ITP design enables a sustained Arctic observation program in the spirit of the Argo program, which is now operating in the temperate oceans (http://www.argo.ucsd.edu/). Ideally, a loose array of approximately 20 of these ITPs and/or comparable instruments can be maintained throughout the ice-covered Arctic Ocean to observe the annual and interannual variations of the upper ocean (Fig. 10).

In collaboration with other groups in the interna-

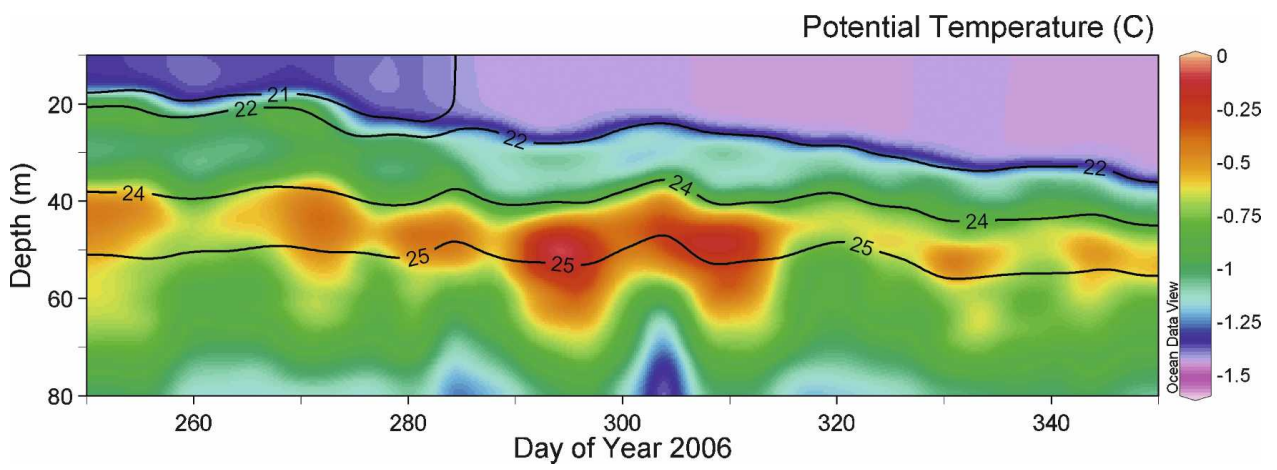

FIG. 8. Potential temperature section from ITP 5 showing the winter mixed layer deepening in a region of the central Canada Basin between 8 Sep and 16 Dec 2006. The profiles contoured have a temporal resolution of $6 \mathrm{~h}$. 


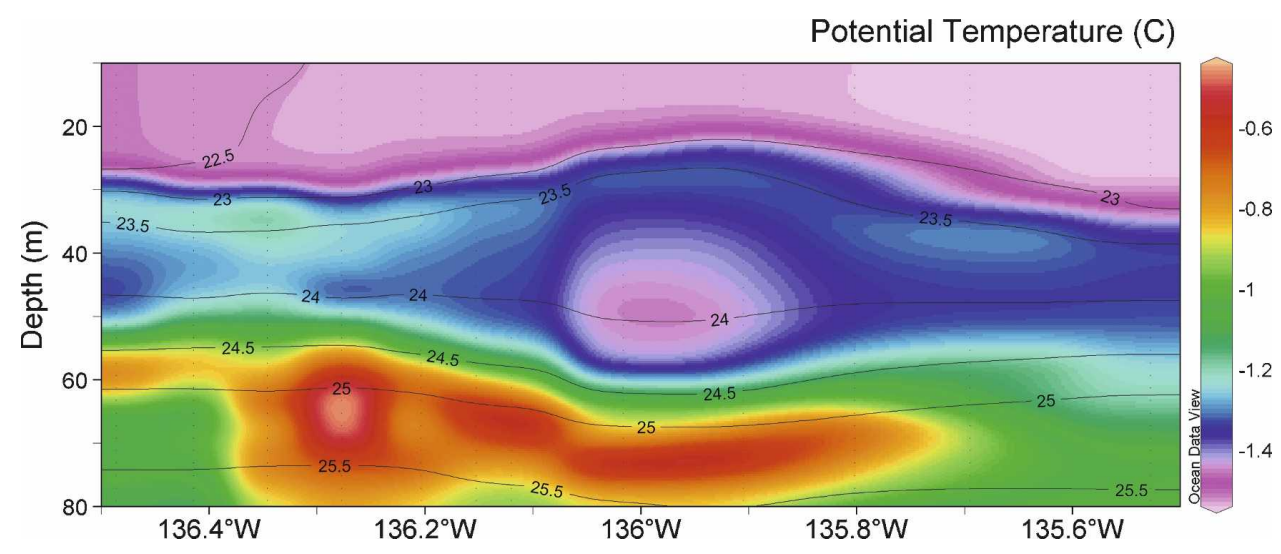

FIG. 9. Potential temperature section from ITP 3 . A cold anticyclonic eddy is clearly visible at about $136^{\circ} \mathrm{W}$, centered around $50-\mathrm{m}$ depth. The eddy is approximately $10 \mathrm{~km}$ in diameter and horizontal ITP profile spacing is about $2.5 \mathrm{~km}$.

tional polar research community, initialization of just such an array of IBOs has begun to yield sustained observations that contribute to the AON. As with several of the prototype instruments, future ITPs will continue to be deployed together with IMB and AOFB buoys. The IMB acquires time series of ice- temperature profiles and measures the growth and ablation of sea ice (and snow) at the top and bottom ice surfaces, and also includes air temperature and barometric pressure sensors. The AOFB measures vertical heat, salinity, and momentum fluxes just below the ice-ocean interface. The trio of buoys is thus capable of returning

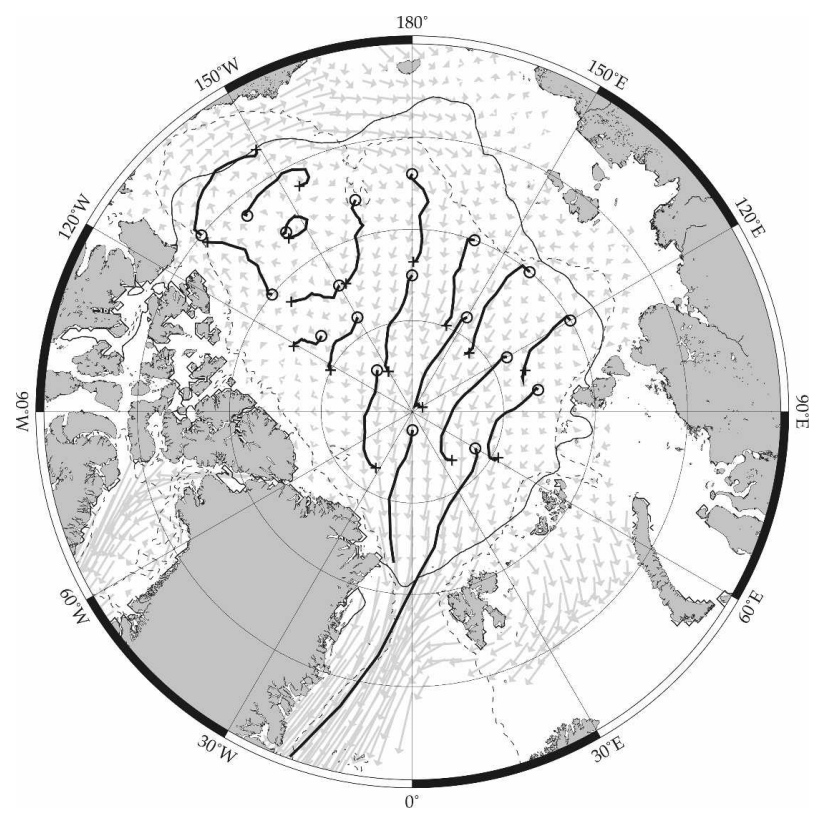

FIG. 10. Simulated drift tracks for $1 \mathrm{yr}$ from 19 ITPs deployed in the Arctic and forced with climatological monthly ice drift vectors from the IABP. Circles mark start locations and crosses mark simulated locations after $1 \mathrm{yr}$. information about the surface atmosphere, ice cover, and ocean water properties down to $\sim 700-\mathrm{m}$ depth. Joint analysis of the data from these IBOs is under way.

Together with European investigators involved in the Developing Arctic Modeling and Observing Capabilities for Long-term Environment Studies (DAMOCLES) program and Japanese scientists, 12 new ITPs were deployed in 2007 in addition to several POPS, IMBs, AOFBs, and other drifting instrument systems. As with previous ITPs, the information acquired from these new systems is being shared publicly in real time from the WHOI ITP Web site (http://www.whoi.edu/itp). Longer term, we envision repeated seedings of IBO instrument clusters annually to sustain the nascent Arctic Observing Network observations of interannual variability and climate change. Future ITP development plans include exploiting the two-way capability of the telemetry system to allow users to modify the sampling schedule of the profiler. The addition of a current measuring device on the profiler package is also underway; integration of meteorological sensor packages, subsurface fixed-depth modules, and subsurface acoustic systems are also being considered. In particular, the combination of subsurface acoustics with the Iridium telemetry could constitute a telecommunications link through the surface ice pack and serve as a future backbone for two-way transmissions to buoys, AUVs, and subsurface moorings in the Arctic Ocean.

Acknowledgments. Many WHOI engineers, technicians, and machinists provided expertise to this project, including Ken Doherty, Dan Frye, Keith von der Heydt, Terry Hammar, John Kemp, Don Peters, Neil McPhee, Kris Newhall, Jim Ryder, Steve Lerner, Will Ostrom, and Hugh Poponoe, as well as Chris Linder for Web page development. The adaptation of the MMP 
engine to the ITP profiler was performed by Mike Mathewson, Gwyneth Packard, Tim Shanahan, and Mark Belcher at McLane Research Laboratories. We also acknowledge the technical assistance provided by Sea-Bird Electronics and Webb Research Corporation during the development effort. We are grateful to our colleagues from the Institute of Ocean Sciences and from the Japan Agency for Marine-Earth Science and Technology for collaborating on the JWACS field programs, and the Canadian Coast Guard and the captains, officers, and crews of the CCGS Louis S. St. Laurent for icebreaker and helicopter support during the deployments. Initial development of the ITP concept was supported by the Cecil H. and Ida M. Green Technology Innovation Program. Funding for construction and deployment of the prototype ITPs was provided by the National Science Foundation Oceanographic Technology and Interdisciplinary Coordination (OTIC) Program and Office of Polar Programs (OPP) under Grant OCE-0324233. Continued support has been provided by the OPP Arctic Sciences Section under Awards ARC-0519899 and ARC-0631951, and internal WHOI funding. Any opinions, findings, and conclusions or recommendations expressed in this publication are those of the authors and do not necessarily reflect the views of the National Science Foundation.

\section{REFERENCES}

ACIA, 2004: Impacts of a Warming Arctic-Arctic Climate Impacts Assessment. Cambridge University Press, $144 \mathrm{pp}$.

Doherty, K. W., D. E. Frye, S. P. Liberatore, and J. M. Toole, 1999: A moored profiling instrument. J. Atmos. Oceanic Technol., 16, 1816-1829.

Gobat, J. I., and M. A. Grosenbaugh, 2000: WHOI cable, version 2.0: Time domain simulation of moored and towed oceanographic systems. Woods Hole Oceanographic Institution Tech. Rep. WHOI-2000-08, 89 pp.
Honjo, S., T. Takizawa, R. Krishfield, J. Kemp, and K. Hatakeyama, 1995: Drifting buoys make discoveries about interactive processes in the Arctic Ocean. Eos, Trans. Amer. Geophys. Union, 76, 209.

Johnson, G. C., J. M. Toole, and N. G. Larson, 2007: Sensor corrections for Sea-Bird SBE-41CP and SBE-41 CTDs. J. Atmos. Oceanic Technol., 24, 1117-1130.

Kikuchi, T., K. Hatakeyama, K. Shimada, T. Takizawa, and J. Morison, 2002: Oceanographic observation under the multiyear ice of the Arctic Ocean using J-CAD (JAMSTEC Compact Arctic Drifter). Proc. 17th Int. Symp. on Okhotsk Sea and Sea Ice, 54-59.

_, J. Inoue, and D. Langevin, 2007: Argo-type profiling float observations under the Arctic multiyear ice. Deep-Sea Res. I, 54, 1675-1686.

Krishfield, R., and Coauthors, 2006: Design and operation of the WHOI Ice-Tethered Profiler for real-time seawater observations in the Polar Oceans. WHOI Tech. Rep. WHOI-2006-11, $81 \mathrm{pp}$.

Morison, J. H., S. P. Burke, H. Steltner, and R. Andersen, 1982: Salargos temperature-conductivity buoys. Proc. IEEE, 14, 1255-1260.

— , K. Aagaard, and M. Steele, 2000: Recent environmental changes in the Arctic: A review. Arctic, 53, 4.

Morrison, A. T., III, J. D. Billings, and K. W. Doherty, 2000: The McLane Moored Profiler: An autonomous platform for oceanographic measurements. Proc. OCEANS 2000, Vol. 1, Providence, RI, MTS/IEEE/, 353-358.

Newhall, K., J. Kemp, D. Peters, and R. Krishfield, 2007: Deployment operation procedures for the WHOI Ice-Tethered Profiler. WHOI Tech. Rep. WHOI-2007-05, 48 pp.

Proshutinsky, A., A. Plueddemann, J. Toole, and R. Krishfield, Eds., 2004: Ice-Based Observatories: A Strategy for Improved Understanding of the Arctic Atmosphere-Ice-Ocean Environment within the Context of an Integrated Arctic Observing System. Woods Hole Oceanographic Institution, 65 pp.

Timmermans, M.-L., J. Toole, A. Proshutinsky, R. Krishfield, and A. Plueddemann, 2008: Eddies in the Canada Basin, Arctic Ocean, observed from ice-tethered profilers. J. Phys. Oceanogr., 38, 133-145.

Toole, J., and Coauthors, 2006: Ice-tethered profilers sample the upper arctic ocean. Eos, Trans. Amer. Geophys. Union, 87, 41, doi:10.1029/2006EO410003. 